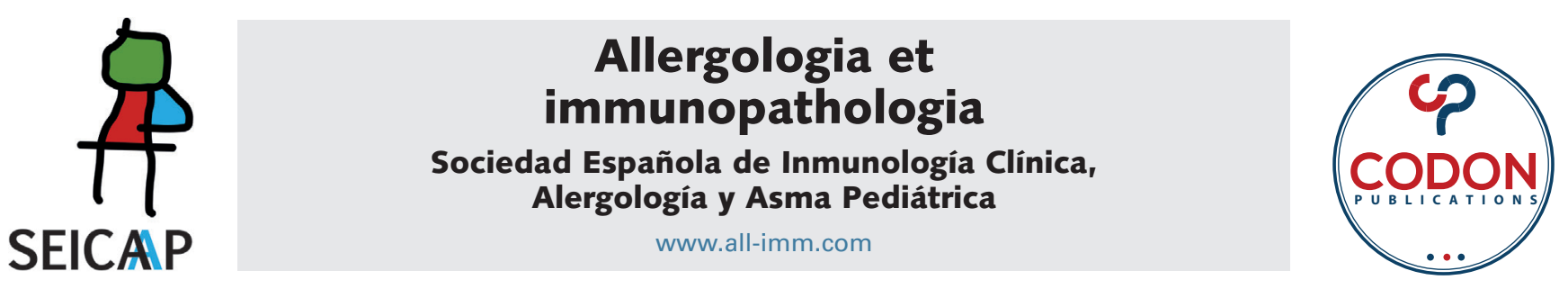

ORIGINAL ARTICLE

\title{
Evaluation of atopy schools for parents
}

\section{Laura García-Soto ${ }^{a}$, Rafael Martín-Masot ${ }^{\mathrm{b}}$, Beatriz Espadafor-López ${ }^{\mathrm{c}}$, Ana María Martínez-Cañavate Burgos ${ }^{\mathrm{d} *}$, Jesús Tercedor-Sánchez ${ }^{\mathrm{c},}$}

${ }^{a}$ Centro Salud Coín, Málaga, Distrito Málaga-Guadalhorce, Spain

bUGC Pediatría, Hospital Regional Universitario de Málaga, Málaga, Spain

'Unidad de Dermatología, Hospital Universitario Virgen de las Nieves, Granada, Spain

dUnidad de Alergología Infantil, Hospital Universitario Virgen de las Nieves, Granada, Spain

eInstituto de Investigación Biosanitaria ibs, Granada, Spain

Received 7 April 2020; Accepted 21 September 2020

Available online 1 March 2021

\section{KEYWORDS}

atopic dermatitis;

Atopy School;

therapeutic

education

\begin{abstract}
Introduction: Atopic dermatitis is a highly prevalent chronic disorder. Therapeutic education in diseases of this kind is essential in order to improve patient management and prognosis. A study was conducted regarding parent satisfaction following educational sessions in an Atopy School organized by a multidisciplinary team.

Material and methods: E-mail surveys with variables scored by means of a Likert scale were administered among the parents participating in the workshops organized by the Atopy School. The educational program comprised four sessions with a duration of 4 hours.

Results: Ninety-five percent of the parents were satisfied after participating in the workshops, and were of the opinion that the therapeutic education received was useful for improving control of the illness of their children. Likewise, $85 \%$ were satisfied or very satisfied with the help received in the sessions for control of the disease during flare-ups, and $90 \%$ considered the data and advice received in the sessions to be of use in improving quality of life of both the children and the family as a whole.

Conclusions: The Atopy School afforded caregiver empowerment, and the parents were satisfied and felt more secure in dealing with the disease of their children-thereby improving the prognosis and quality of life.
\end{abstract}

(C) 2021 Codon Publications. Published by Codon Publications.

*Corresponding author: Ana Martínez-Cañavate, Hospital Uniersitario, Materno Infantil, Virgen De Las Nieves Avda. Fuerzas Armadas sn. 18014 Granada, Spain. Email address: info@all-imm.org 


\section{Introduction}

Atopic dermatitis is a chronic skin disorder that affects approximately $20 \%$ of the pediatric population worldwide. Its incidence moreover appears to be increasing, particularly in developed countries and western societies. ${ }^{1}$ Atopic dermatitis generally manifests before 5 years of age and is slightly more common among females. A range of pathogenic factors are involved, including particularly skin barrier alterations secondary to genetic mutations related to filaggrin and the host immune response. A family history of atopic disease, including asthma and allergic rhinitis, predisposes to the development of atopic dermatitis and suggests the existence of shared underlying genetic and physiopathological mechanisms. ${ }^{2}$ The clinical presentation of atopic dermatitis varies greatly depending on the age of the patient and the degree of activity of the disease. The diagnosis is based on the clinical history and on the morphology and distribution of the skin lesions. Adequate management is crucial for reducing the symptoms, avoiding flare-ups, and improving the quality of life of the patients, which is adversely affected as a result of symptoms that are difficult to control. Treatment seeks to avoid the triggering factors (allergens), maintain adequate skin hydration, and control skin inflammation with the administration of topical immune modulators and corticosteroids. However, adequate education of the patients and their relatives in dealing with the disease is also essential in order to avoid flare-ups, ensure correct adherence to therapy, and control the symptoms in the long term.

Therapeutic education is fundamental in chronic diseases. According to the World Health Organization, it helps patients with conditions of this kind to acquire or maintain the necessary skills as best as possible. ${ }^{3}$ Therapeutic education has been shown to contribute effectively to prevent complications, improve quality of life, and favor adherence to treatment in many disease settings such as diabetes, asthma, and cardiovascular disorders. ${ }^{4}$ This is important because adherence to treatment in general is low in patients with chronic disorders, and especially in those with skin conditions, ${ }^{5,6}$ where treatment must be applied regularly and mostly in topical form. In the case of atopic dermatitis, the fact that corticosteroids constitute the basis of therapy poses an added problem because of fear and concern about the possible adverse effects that may occur; in consequence, adherence to treatment is often poor or only partial. ${ }^{7}$ This situation requires patients and their families to acquire the knowledge and skills needed for self-evaluation and adjustment of therapy to each moment in the course of the disease.

The present study was carried out to evaluate satisfaction among the parents of children with atopic dermatitis following participation in workshops organized by an Atopy School and designed to improve control of the disease and quality of life through adequate therapeutic education.

\section{Material and methods}

The study included parents and/or caregivers who were willing to participate in the workshops via an e-mail address provided in the Primary Care Pediatrics, Dermatology and Pediatric Allergology clinics. The parents and/or caregivers were requested to specify the gender and age of the child and the degree of severity of atopic dermatitis, diagnosed by a healthcare professional familiarized with the management of atopic dermatitis, based on the SCORing Atopic Dermatitis (SCORAD) severity assessment scale. ${ }^{8}$

Four educational sessions with a duration of 4 hours in the afternoon were organized by the Atopy School, with a maximum participation of 20 people in each session. The sessions addressed five main topics: general skin care, topical treatments, concern about corticosteroids, allergological assessment, and psychological orientation for parents and children. The sessions were taught by a multidisciplinary team composed of dermatologists, a primary care pediatrician, psychologist, and pediatric allergologist. After the sessions, the topics were discussed among the parents, caregivers, and healthcare professionals.

After completion of all the sessions, a survey was administered via e-mail, comprising four questions with six possible answers scored by means of a Likert scale as follows: 0 (very dissatisfied), 1 (not satisfied), 2 (little satisfied), 3 (neither satisfied nor dissatisfied), 4 (satisfied), and 5 (very satisfied) (Figure 1). The questions aimed to determine whether the parents/caregivers considered the information they received to have helped them to

1. Do you consider the information received during the sessions to be practical?

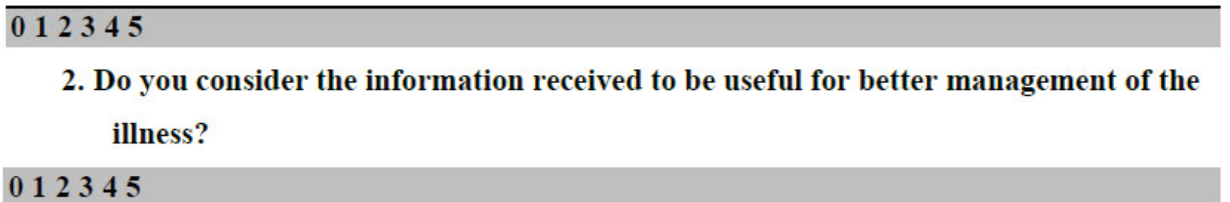

3. Do you consider the information received to have facilitated control of the flare-ups of atopic dermatitis?

012345
4. Do you consider the information received to have improved the quality of life of
your child and that of the rest of the family?
012345

Figure 1 Multiple response survey used in the study. 
better manage the disease, to facilitate control of the illness during flare-ups, and whether it had contributed to improve the quality of life of the patients and their families. Parents/caregivers failing to complete the survey were excluded from the study.

\section{Results}

A total of 84 parents/caregivers participated in the four sessions held during 2018. Forty-two surveys were completed (one per patient). The patients were up to 10 years of age, with a mean age of 4.4 years. Of the patients, $50 \%$ had moderate atopic dermatitis, $33 \%$ had mild atopic dermatitis, and $17 \%$ had severe atopic dermatitis (Table 1 ).

The scores corresponding to each question of the survey are reported in Table 2. Eighty-five percent of the parents claimed to be very satisfied with the information received during the sessions and considered it to be practical. Likewise, $95 \%$ were of the opinion that the information received was of help in better managing the illness, and

Table 1 Clinical and demographic characteristics of the patients.

\begin{tabular}{lcc}
\hline Gender (n, \%) & & \\
Female & 24 & $57 \%$ \\
Male & 18 & $43 \%$ \\
\hline Age (mean, range) & 4.4 & $0-10$ \\
\hline SCORAD (n, \%) & & \\
$\quad$ Mild & 14 & $33 \%$ \\
Moderate & 21 & $50 \%$ \\
Severe & 7 & $17 \%$ \\
\hline SCORAD, SCORing atopic dermatitis. & &
\end{tabular}

$85 \%$ were satisfied or very satisfied with the help received in the sessions for control of the disease during flare-ups. In turn, 90\% considered the data and advice provided in the sessions to have been of help in improving the quality of life of both the patients and their families (Figure 2).

In the case of the parents with children presenting moderate atopic dermatitis, $95 \%$ were satisfied or very satisfied with the help received in the sessions for management of the disease and control of the flare-ups, and $85 \%$ considered that the quality of life of both the patients and their families had improved as a result of what had been learned from the sessions.

Similar results were obtained in the group of parents with children presenting severe atopic dermatitis: $100 \%$ considered the information received to be useful, and $85 \%$ were satisfied or very satisfied with the information about managing the disease. All the parents considered that the sessions had helped them to better control the flare-ups,

Table 2 Scores obtained with the study survey.

\begin{tabular}{lllllllll}
\hline & 0 & 1 & 2 & 3 & 4 & 5 \\
\hline $\begin{array}{l}\text { Do you consider the information received } \\
\text { during the sessions to be practical? }\end{array}$ & 0 & 0 & 0 & 1 & 5 & 36 \\
Do you consider the information received & 0 & 0 & 0 & 2 & 16 & 24 \\
to be useful for better management of \\
the illness?
\end{tabular}

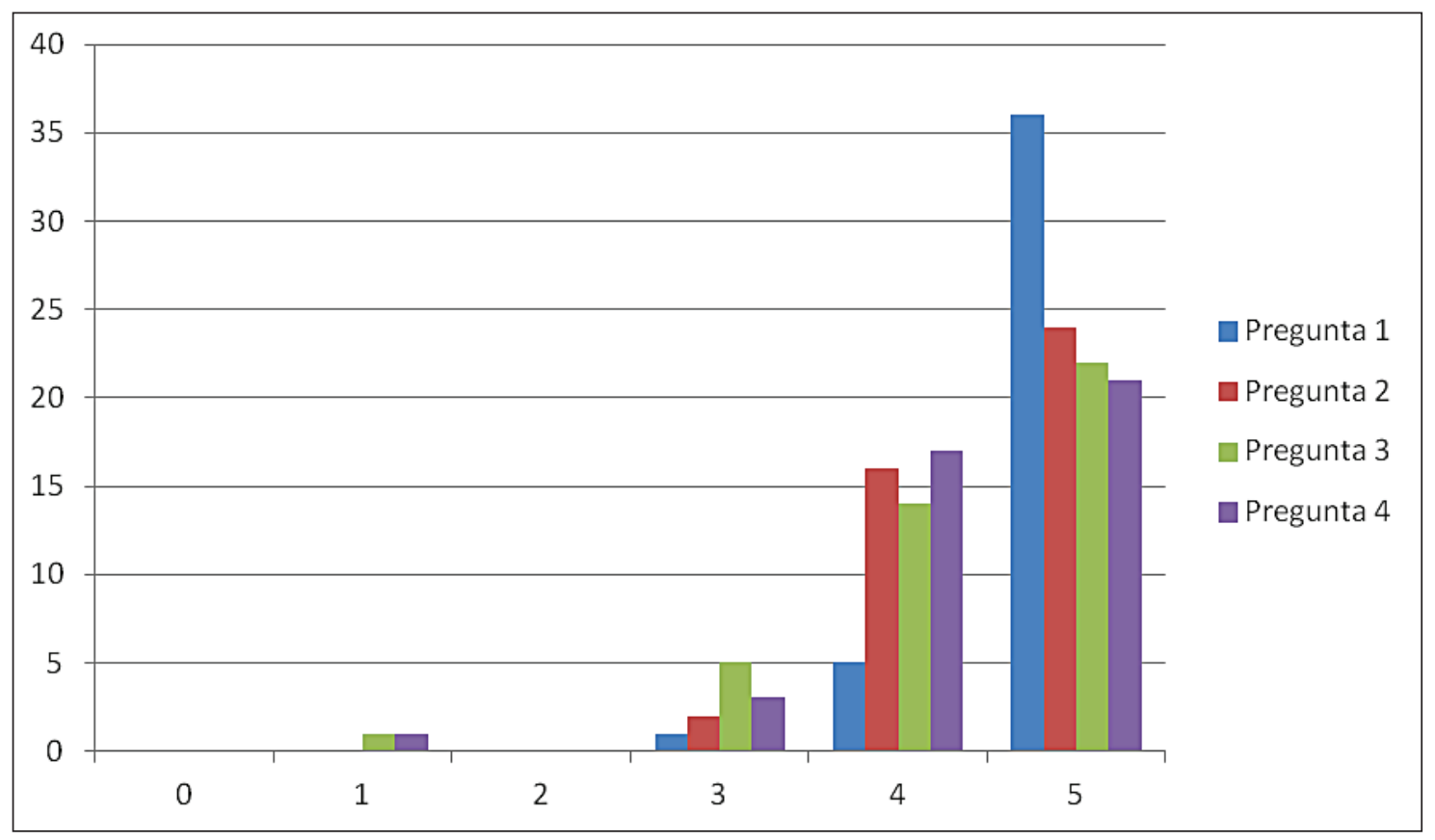

Figure 2 Comparative plot of the scores obtained with each question. 
and $85 \%$ reported improved quality of life of the children after applying the information received.

\section{Discussion}

In our study, about $85-95 \%$ of the surveyed parents/caregivers claimed to be satisfied or very satisfied with the information received during the Atopy School sessions in relation to general skin care, topical treatments and fear of corticosteroid side effects, allergological assessment, and psychological orientation. They considered that the information had been of help in improving the illness of their children, in controlling the flare-ups more effectively, and in improving the quality of life. Although a number of researchers have evidenced the efficacy of therapeutic education in chronic diseases as common as asthma or diabetes, ${ }^{4}$ few studies have addressed its efficacy in the management of atopic dermatitis.

The relevance of therapeutic education in chronic skin diseases has grown in recent years, and a number of studies have evaluated its efficacy in such scenarios. In 2002, Chinn $^{9}$ and Gradwell ${ }^{10}$ published studies on the efficacy of education and follow-up conducted by a nurse with expertise in dermatology in improving the quality of life of patients with atopic dermatitis. Both studies evidenced a positive impact of such educational measures. However, these findings were not confirmed in subsequent controlled trials ${ }^{11-13}$ in which significant improvement was observed in the severity of disease but not in quality of life. Likewise, another study ${ }^{14}$ compared the experiences with therapeutic education in 11 countries referred to the management of atopic dermatitis and found that although there were differences among the countries, the experts agreed on the need to integrate education into the management of atopic dermatitis.

Recommendations have recently been published ${ }^{15}$ on what therapeutic education in atopic dermatitis should focus on in relation to the topics addressed by the Atopy School sessions in our study. The main educational topics which the authors considered to be important included the severity of the disease, its impact on activities of daily living, and the adherence barriers involved (e.g., concern about corticosteroids, lack of time, forgetfulness, and complexity and cost of treatment). Therapeutic education programs should be focused on patients, based on evidence, and integrated into the management of atopic dermatitis. Such educational measures in turn should be implemented by a multidisciplinary team within the context of well-defined and programmed sessions. ${ }^{15}$

The present study has limitations, including its descriptive design, with evaluation being limited to parent satisfaction with regard to improved management of the disease and quality of life. The number of surveys was moreover limited, and no patient follow-up was carried out; as a result, the applicability of the therapeutic education strategy was not confirmed by clinical improvement of the disease. Likewise, the surveys did not take into account the prior knowledge of the parents regarding the pathogenesis of the disease or the function of the prescribed drug treatments. Nevertheless, our study contributes significant data that add to those of previous publications ${ }^{9,10}$ in which improvement of quality of life has been analyzed after therapeutic interventions.

Based on our results, it can be concluded that therapeutic education is able to increase parent information about atopic dermatitis and eliminate certain myths and false beliefs regarding treatment that can result in a lack of adherence. Furthermore, empowerment of the caregivers, who receive information and resources allowing them to make decisions regarding patient management, ${ }^{16}$ improves perception of the care and quality of life of the children. We therefore believe that more Atopy Schools should be incorporated into healthcare centers, with multidisciplinary teams to help patients and their caregivers to better understand the disease and its management. Nevertheless, further controlled studies are needed to confirm the applicability of therapeutic education in relation to the management and prognosis of chronic skin disorders such as atopic dermatitis.

\section{References}

1. Flohr C, Mann J. New insights into the epidemiology of childhood atopic dermatitis. Allergy. 2014;69:3-16. https://doi. org/10.1111/all.12343; https://doi.org/10.1111/all.12270

2. Fishbein $A B$, Silverberg $\mathrm{JI}$, Wilson EJ, Ong PY. Update on atopic dermatitis: diagnosis, severity assessment, and treatment selection. J Allergy Clin Immunol Pract. 2020;8:91-101. https://doi.org/10.1016/j.jaip.2019.06.044

3. World Heatlh Organization. Regional Office for Europe. (1998). Therapeutic patient education: continuing education programmes for healthcare providers in the field of prevention of chronic diseases: report of a WHO Working Group. Copenhagen: WHO Regional Office for Europe.

4. Weingarten SR, Henning JM, Badamgarav E, et al. Interventions used in disease management programmes for patients with chronic illness - Which ones work? Metaanalysis of published reports. BMJ. 2002;325:925. https://doi.org/10.1136/ bmj.325.7370.925

5. Osterberg L, Blaschke T. Adherence to medication. N Engl J Med. 2005;353:487-497. https://doi.org/10.1056/NEJMra050100

6. Krejci-Manwaring J, Tusa MG, Carroll C, et al. Stealth monitoring of adherence to topical medication: adherence is very poor in children with atopic dermatitis. J Am Acad Dermatol. 2007;56:211-216. https://doi.org/10.1016/j.jaad.2006.05.073

7. Li Y, Han T, Li W, Li Y, Guo X, Zheng L. Awareness of and phobias about topical corticosteroids in parents of infants with eczema in Hangzhou, China. Pediatr Dermatol. 2018;35:463467. https://doi.org/10.1111/pde.13527

8. European Task Force on Atopic Dermatitis. Severity scoring of atopic dermatitis: the SCORAD index. Consensus report of the European Task Force on Atopic Dermatitis. Dermatology. 1993;186:23-31. https://doi.org/10.1159/000247298

9. Chinn DJ, Poyner T, Sibley G. Randomized controlled trial of a single dermatology nurse consultation in primary care on the quality of life of children with atopic eczema. $\mathrm{Br} J$ Dermatol. 2002;146:432-439. https://doi. org/10.1046/j.1365-2133.2002.04603.x

10. Gradwell C, Thomas KS, English JS, et al. A randomized controlled trial of nurse follow-up clinics: do they help patients and do they free up consultants' time? Br J Dermatol. 2002;147:513517. https://doi.org/10.1046/j.1365-2133.2002.04901.x

11. Shaw M, Morrell DS, Goldsmith LA. A study of targeted enhanced patient care for pediatric atopic dermatitis (STEP PAD). Pediatr Dermatol. 2008;25:19-24. https://doi. org/10.1111/j.1525-1470.2007.00575.x 
12. Staab D, Diepgen TL, Fartasch $M$, et al. Age related, structured educational programmes for the management of atopic dermatitis in children and adolescents: multicentre, randomised controlled trial. BMJ. 2006;332:933-938. https://doi. org/10.1136/bmj.332.7547.933

13. Grillo M, Gassner L, Marshman G, et al. Pediatric atopic eczema: the impact of an educational intervention. Pediatr Dermatol. 2006;23:428-436. https://doi.org/10.1111/j.1525-1470.2006.00277.x

14. Stalder JF, Bernier C, Ball A, de Raeve L, Gieler U, Deleuran M, et al. Therapeutic patient education in atopic dermatitis:
Worldwide experiences. Pediatr Dermatol. 2013;30:329-333. https://doi.org/10.1111/pde.12024

15. Barbarot S, Bernier C, Deleuran M, De Raeve L, Eichenfield L, El Hachem M, et al. Therapeutic patient education in children with atopic dermatitis: position paper on objetives and recommendations. Pediatr Dermatol. 2013;30:199-206. https:// doi.org/10.1111/pde.12045

16. Domínguez-Cruz JJ, Pereyra-Rodríguez JJ, Ruíz Villaverde R. Empoderamiento y dermatología. Actas Dermosifliogr. 2018; 109:133-9. https://doi.org/10.1016/j.ad.2017.09.008 